\title{
MODELING ONSET OF GLACIATION
}

\author{
by
}

Thomas J. Crowley

(Applied Research Corporation, 305 Arguello Drive, College Station, TX 77840, U.S.A.)

and

Gerald R. North

(Climate System Research Program, Department of Meteorology, Texas A \& M University, College Station, TX 77843, U.S.A.)

\section{ABSTRACT}

Numerous studies have shown that climate has varied between ice-free and glaciated states, with transitions of ten marked by abrupt steps. We summarize some modeling studies that have attempted to explain elements of the long-term trend and discuss a particular model for abrupt transitions that involves instabilities due to albedo discontinuities at the snow/ice edge.

\section{INTRODUCTION}

Past climates have fluctuated several times between times of apparently ice-free conditions and times with polar ice caps (e.g. Crowley, 1983). For example, numerous studies on the evolution of Cenozoic climate indicate that there has been a long-term trend toward cooler climates (e.g. Fig. 1). A number of key transitions are marked by relatively abrupt, steplike changes. In this paper we will examine modeling progress in simulating the long-term changes and discuss one class of climate models that may explain some of the rapid transitions.

\section{LONG-TERM TREND}

At least four processes may be influencing the long-term evolution of climate - changing levels of atmospheric carbon dioxide; variations in poleward ocean heat transport; varations in orography; and fluctuations in

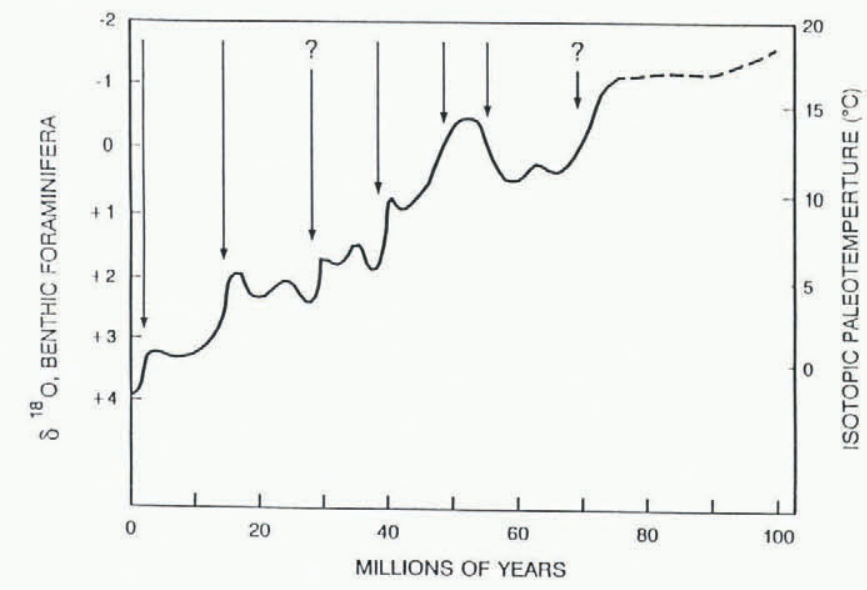

Fig. 1. The deep-sea ${ }^{18} \mathrm{O}$ record for the last 100 million years (Ma). The long-term trend is thought to reflect cooling in high latitudes. Note that abrupt steps mark the long-term trend. ${ }^{18} \mathrm{O}$ record after Douglas and Woodruff (1981). the seasonal cycle of landmasses as a result of change in land-sea distribution. For example, climate and geochemical model studies suggest that $\mathrm{CO}_{2}$ levels were significantly higher in the past (Berner and others, 1983; Barron and Washington, 1985) and may have been responsible for warm temperatures of the mid-Cretaceous $100 \mathrm{Ma}$ (million years) ago. Other modeling studies indicate that uplift of the Himalayas and Rockies and closing of the central American isthmus may have significantly influenced the atmosphere and ocean circulation (Kutzbach and others, 1989; Maier-Reimer and others, 1989; Ruddiman and others, 1989).

Changes in land-sea distribution can also affect the long-term evolution of climate (Barron, 1985; Crowley and others, 1986, 1987). Due to the different heat capacities of land and water, summer temperatures are higher over land, and the larger the land mass, the higher the temperature. This feature can be modeled with seasonal two-dimensional energy balance models (EBMs); cf. North and others (1983). Sensitivity experiments indicate that the EBMs are comparable to GCMs in terms of changes in seasonal forcing (Hyde and others, 1989, 1990).

Changes in past land-sea distribution due to continental drift should have significantly affected the seasonal cycle on landmasses. For example, Crowley and others (1986) calculate large reductions in summer termpatures in key areas that presently have permanent ice sheets (Greenland

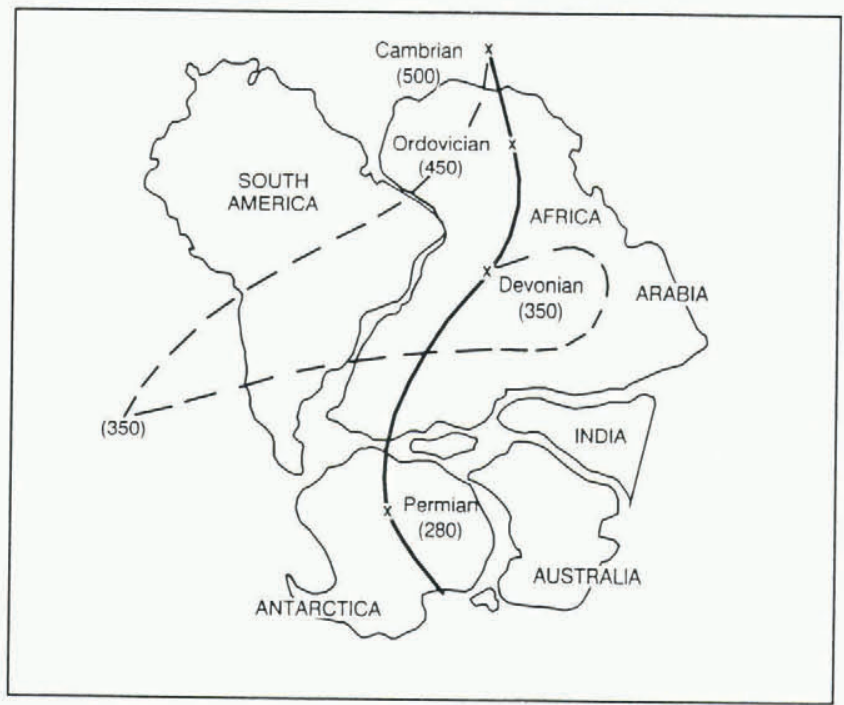

Fig. 2. Postulated Paleozoic apparent polar wander paths of the South Pole with respect to Gondwanaland. Dashed line indicates alternate path based on different data sources. Numbers in parentheses are ages in Ma. (From Crowley and others, 1987; adapted from Morel and Irving, 1978.) 


\section{SUMMER TEMPERATURE, SOUTH POLE (IDEALIZED SUPERCONTINENT)}

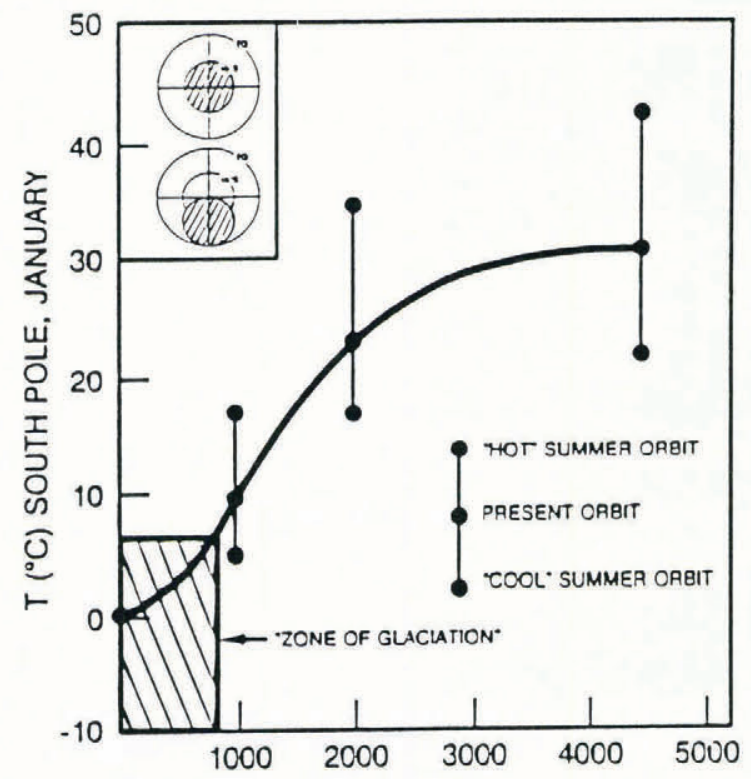

\section{DISTANCE $(\mathrm{km})$ OF POLE FROM EDGE OF CONTINENT}

Fig. 3. Modeled summer temperature at the South Pole for different positions of an idealized supercontinent (see inset), based on seasonal two-dimensional energy balance model calculations. Heavy line represents temperatures for the present orbital configuration. Variations around this value represent changes in forcing compatible with the maximum changes in orbital configurations for the Pleistocene (highest points, "hot summer" orbit; lowest points, "cool summer" orbit). Diagonal striping marks the postulated region of parameter space affected by glaciation if ice-albedo feedback were included. (From Crowley and others, 1987.)

and Antarctica). Such decreases may have allowed inception of ice sheets. A more dramatic example involves the migration of the Paleozoic supercontinent of Gondwanaland across the South Pole (Fig. 2). Due to the differences in heat capacity of land and ocean, there are large changes in polar temperatures depending on whether the pole is situated near the edge or in the center of the landmass (Fig. 3). Some geographic configurations may result in summer temperatures too high to allow glacial inception.

The above studies indicate that it is unlikely that the long-term evolution in past climates will be explained by only one factor. One of the goals of paleoclimatology is to integrate the effects of all of the above changes and then compare the results with the long-term history mapped by geologists. A substantial amount of additional work is required to reach this goal.

\section{ABRUPT TRANSITIONS}

Another feature of past climates involves the abrupt steps (Fig. 1). The best evidence, for these steps is in the Cenozoic (last $65 \mathrm{Ma}$ ), but they probably occurred earlier. There are now at least three classes of models that exhibit unstable behavior which may explain the transitions. The first class focuses on thermohaline instabilities in areas of deep-water formation (Peterson, 1979; Broecker and others, 1985; cf. Bryan, 1986). The second class focuses on nonlinear interactions in the ocean-ice-atmosphere system (e.g. Ghil and Le Treut, 1981; Saltzman and Sutera, 1984). The third class of models addresses instabilities triggered by discontinuous albedo changes at the margin of permanent snow/ice cover, i.e. the "small ice-cap instability" (SICI); (North, 1984; North and Crowley, 1985). Because one of us (G.N.) has investigated the latter phenomenon in considerable detail over the years, in the following section we will briefly discuss it as representing one example of a class of models exhibiting unstable behavior.
An example of model behavior of the third type is shown in Figure 4, which illustrates different stable branches of an energy balance model (EBM) with snowalbedo feedback (cf. North, 1975; North and others, 1981). Due to the albedo discontinuity at the snow line, the model exhibits discontinuous behavior as some radiation balance parameter is taken past critical points $B$ and $C^{\prime}$. In the course of crossing such a threshold by the slow change in any parameter affecting the radiation budget, the ice cover area changes abruptly (of course, the growth of ice volume is determined by the mass balance of the ice cap which is considered beyond the scope of this kind of model). Further studies with stochastic forcing of an EBM (Crowley and North, 1988) indicate that temperature range and autocorrelation increase as the mean climate state approaches a critical point.

Figure 4 tells us that stable ice caps smaller than the critical size cannot exist in this type of model. The reason for this peculiar behavior is an interaction between the albedo discontinuity at the snow-line edge and the existence of a fundamental length scale in the simple mean annual EBMs with diffusive heat transport. Consider the following example. Suppose that changes in continental drift caused a gradual reduction in summer temperatures such that at some point temperatures did not rise above zero in one area. In this area permanent snow cover would result. Due to the higher albedo of snow and ice, temperatures would now drop significantly below zero on the now-permanent snow patch.

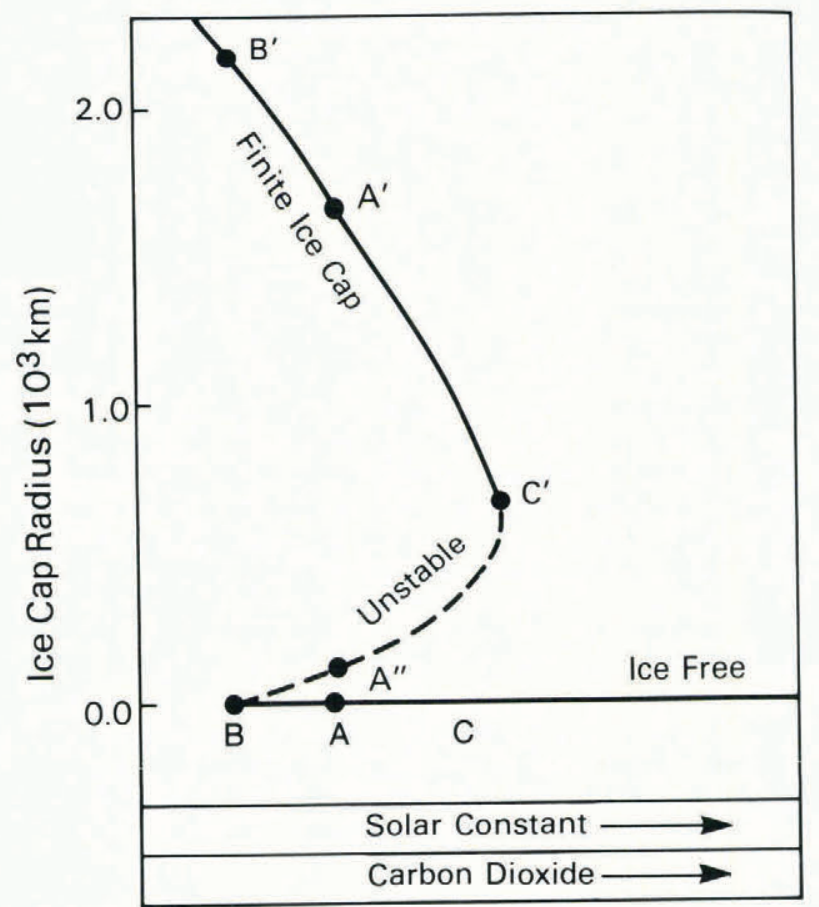

Fig. 4. Schematic graph of equilibrium solutions of an energy balance model with ice-albedo feedback. The dependent variable is the ice-cap radius and the independent variable is the solar constant (or carbon dioxide) increasing to the right. (From North and Crowley, 1985.)

The effect of the "point sink" of heat would extend beyond the limits of the original snow-ice edge, now depressing temperatures below zero in these regions. The effective length scale of the perturbation in polar regions is on the order of 1000 to $2000 \mathrm{~km}$ (North, 1984; Manabe and Broccoli, 1985; cf. Hansen and Lebedeff, 1987); physically, it can be interpreted as the distance a heat anomaly can diffuse before it is radiatively damped away (Fig. 5). The length scale of the temperature perturbation therefore dictates the minimum size of a stable ice sheet as about $1500 \mathrm{~km} \mathrm{(cf.} \mathrm{Fig.} \mathrm{4).} \mathrm{All} \mathrm{ice} \mathrm{sheets} \mathrm{in} \mathrm{between} 0 \mathrm{~km}$ and $1500 \mathrm{~km}$ would be unstable (cf. Cahalan and North, 1979), with the climate state therefore converging on one of two solutions - no ice or an ice sheet of $1500 \mathrm{~km}$ radius. This is the physical explanation for SICI. 
GCM/Land Ice Effect-EBM NH Albedo Expt

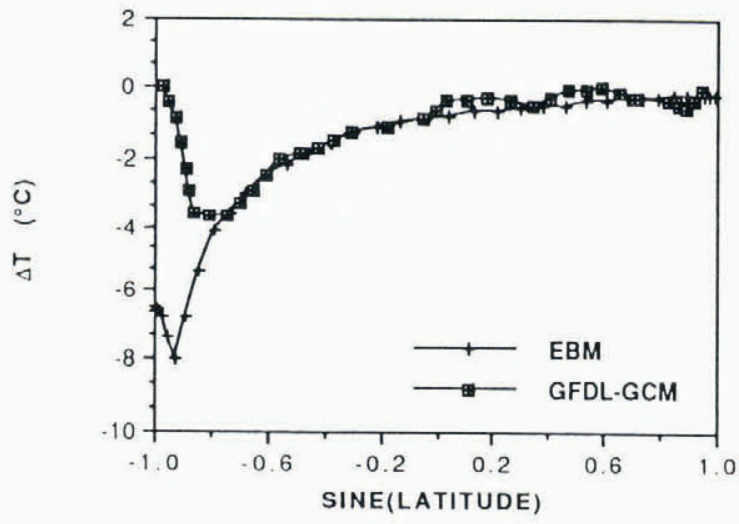

Fig. 5. Example of the length scale effect as modeled in both EBMs and the Geophysical Fluid Dynamics Laboratory general circulation model (GFDL-GCM). For both experiments a "point sink" of heat - northern hemisphere ice sheet - was inserted as a lower boundary condition. Note the limited area affected by the perturbation, and that the far-field response is similar in both the EBM and GCM. GCM results from Broccoli and Manabe (1987); figure from Hyde and others (1989).

The situation just described has been modeled for a planet with no seasons (North, 1975). It leads to a symmetric ice cap centered at the pole. While this configuration is similar to the situation at the South Pole, it lacks certain key ingredients to make a complete theory of Antarctic or Pleistocene glacial inception. Furthermore, we know that the Milankovitch forcing is mainly expressed through changes in the seasonal distribution of insolation. Hence, SICI as described above cannot explain the quasiperiodic glaciations of the Pleistocene.

Consider now a seasonal EBM with land and sea distribution (North and Coakley, 1979; North and others, 1983). The heat capacity contrast between land- and seacovered surfaces has a strong influence on the amplitude of the seasonal cycle in these models: large amplitude over land toward the poles, small over oceans. The summer temperatures then are strongly modulated by the surface type and the latitude. We might consider as a reasonable hypothesis that glaciers can grow when snow cover remains over the local summer. Hence, in this formulation the key feature is the presence or absence of snow over the summer. The nature of the influence function is now modified, since a small patch of snow does not contribute a steady sink for heat in the model. Rather, it is time-dependent because of the seasonal march of insolation. The length scale is now shorter and it depends on surface type, land or ocean. In a nutshell, the length scale is still reasonably large over land but negligibly small over oceans, leading to a complicated structure of the influence function near irregular shorelines. Exploration of seasonal models for abrupt changes in climate is obviously more involved.

There have been two recent attempts to simulate SICI with simple geography and seasonal forcing. For a configuration analogous to Antarctica (symmetric band of land centered on the pole), Mengel and others (1988) found an abrupt transition when values of the forcing (the solar constant) were changed by only $0.01 \%$. The $0.07 \mathrm{~W} \mathrm{~m}^{-2}$ change in forcing is more than three orders of magnitude less than Pleistocene ice volume changes associated with Milankovitch insolation cycles. This work supported earlier studies by Suarez and Held (1979) and Watts and Hayder (1984).

Lin and North (1989) examined the case where a slightly more complicated case involved geography and seasonal forcing (symmetric polar ocean and mid-latitude land strip). The seasonal cycle of the snow line is shown in Figure 6. There are two transitions: first summer snow abruptly covers the polar ocean, then summer snow abruptly covers the continent. These experiments indicate that there may be multiple instabilities in the climate system, and that

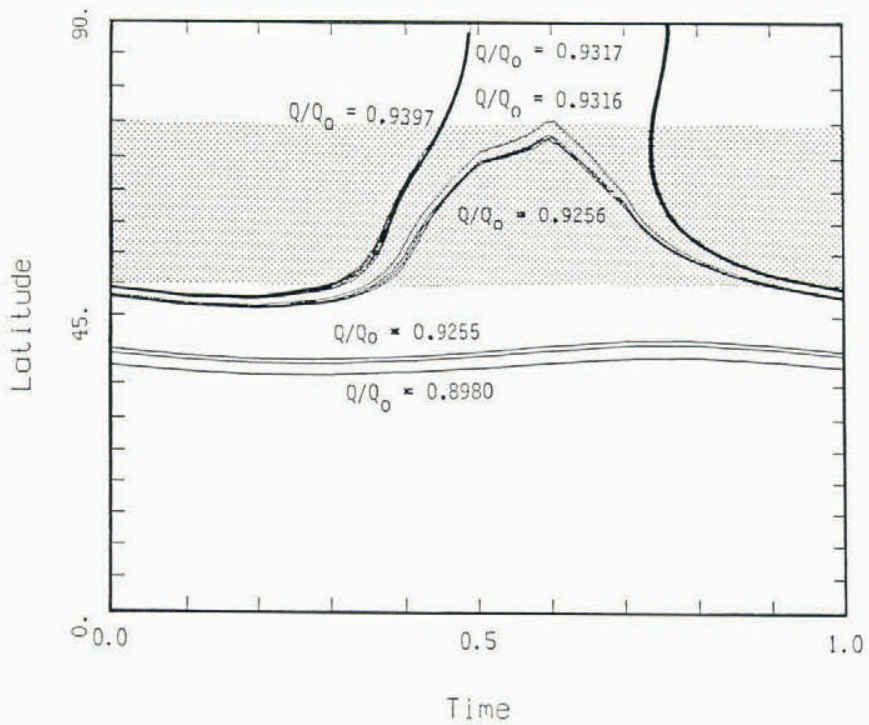

Fig. 6. Seasonal snow-line distribution vs time of year, as calculated with nonlinear energy balance model with idealized geography. Shaded area denotes land. $\mathrm{Q} / \mathrm{Q}_{0}$ refers to proportional changes in effective solar forcing. Note that changes in forcing of 0.0001 can result in seasonally ice-free states and that there is a tendency for "clustering" of instabilities over a relatively small range of parameter space (see text). (From Lin and North, 1989.)

the instabilities may be clustered over a relatively small range of parameter space - the total change in radiative forcing is approximately equivalent to late Pleistocene changes associated with ice-age $\mathrm{CO}_{2}$ fluctuations.

The EBM studies suggest that the planet could undergo abrupt shifts in summer snow cover leading to the sustained growth of instability of continental ice sheets. The studies so far have been with idealized geographies and no hydrological cycle. They can only suggest the existence of discontinuous behavior. Studies with more realistic geography and physics are being developed. Real world behavior may not be discontinuous but the remnant of discontinuity may be steep slopes, etc. The continued study of these idealized models can yield additional insight into the potentially important processes affecting the variation of the Earth's climate.

\section{SUMMARY AND CONCLUSIONS}

Considerable progress has been made in delineating mechanisms reponsible for the long-term evolution of climate. At least four important processes can be identified - changes in $\mathrm{CO}_{2}$, the seasonal cycle on land masses, poleward ocean heat transport, and orography. It remains to be determined how these various pieces of the puzzle fit together. There are at least three classes of models that illustrate unstable behavior and which may explain the abrupt steps of the past. Examples are given of one of these classes. However, the jury is still out as to the relative importance of the different classes.

\section{ACKNOWLEDGEMENTS}

This work was supported by National Science Foundation grants ATM87-22145(TJC) and ATM87-15079 (GRN).

\section{REFERENCES}

Barron, E.J. 1985. Explanations of the Tertiary global cooling trend. Palaeogeogr. Palaeoclimatol. Palaeoecol., 50, 45-61. 
Barron, E.J. and W.M. Washington. 1985. Warm Cretaceous climates: high atmospheric $\mathrm{CO}_{2}$ as a plausible mechanism. In Sundquist, E.T. and W.S. Broecker, eds. The carbon cycle and atmospheric $\mathrm{CO}_{2}$ : natural variations Archean to present. Washington, DC, American Geophysical Union, 546-553. (Geophysical Monograph 32.)

Berner, R.A., A.C. Lasaga, and R.M. Garrels. 1983. The carbonate-silicate geochemical cycle and its effect on atmospheric carbon dioxide over the last 100 million years. Am. J. Sci., 238, 641-683.

Broccoli, A. and S. Manabe. 1987. The influence of continental ice, atmospheric $\mathrm{CO}_{2}$, and land albedo on the climate of the last glacial maximum. Climate Dyn., 1, 87-100.

Broecker, W.S., D.M. Peteet, and D. Rind. 1985. Does the ocean-atmosphere system have more than one stable mode of operation? Nature, 315, 21-26.

Bryan, F. 1986. High-latitude salinity effects and interhemispheric thermohaline circulations. Nature, 323, 301-304.

Cahalan, R.F. and G.R. North. 1979. A stability theorem for energy-balance climate models. J. Atmos. Sci., 36, $1205-1216$.

Crowley, T.J. 1983. The geologic record of climatic change. Rev. Geophys. Space Phys., 21, 828-877.

Crowley, T.J. and G.R. North. 1988. Abrupt climate change and extinction events in Earth history. Science, 240, 996-1002.

Crowley, T.J., D.A. Short, J.G. Mengel, and G.R. North. 1986. Role of seasonality in the evolution of climate over the last 100 million years. Science, 231, 579-584.

Crowley, T.J., J.G. Mengel, and D.A. Short. 1987. Gondwanaland's seasonal cycle. Nature, 329(6142), 803-807.

Douglas, R.G. and F. Woodruff. 1981. Deep sea benthic foraminifera. In Emiliani, C., ed. The sea. Vol. 7. New York, Wiley-Interscience, 1233-1327.

Ghil, M. and H. LeTreut. 1981. A climate model with cryodynamics and geodynamics. J. Geophys. Res., 86(C6), 5262-5270.

Hansen, J. and S. Lebedeff. 1987. Global trends of measured surface air temperature. J. Geophys. Res., 92(D11), 13,345-13,372.

Hyde, W.T., T.J. Crowley, K.-Y. Kim, and G.R. North. 1989. Comparison of GCM and energy balance model simulations of seasonal temperature changes over the past 18,000 years. J. Clim., 2, 864-887.

Hyde, W.T., K.-Y. Kim, T.J. Crowley, and G.R. North. In press. On the relation between polar continentality and climate: studies with a nonlinear energy balance model. $J$. Geophys. Res.

Kutzbach, J.E., P.J. Guetter, W.F. Ruddiman, and W.L. Prell. 1989. The sensitivity of climate to Late Cenozoic uplift in southeast Asia and the American southwest: numerical experiments. J. Geophys. Res., 94(D15), $18,393-18,407$.
Lin, R.-Q. and G.R. North. In press. A study of abrupt climate change in a simple nonlinear climate model. Climate Dyn.

Maier-Reimer, E., T.J. Crowley, and U. Mikolajewicz. In press. Ocean GCM sensitivity experiment with an open Central American isthmus. Paleoceanography.

Manabe, S. and A.J. Broccoli. 1985. The influence of continental ice sheets on the climate of an ice age. $J$. Geophys. Res., 90(D1), 2167-2190.

Manabe, S. and R.J. Stouffer. 1988. Two stable equilibria of a coupled ocean-atmosphere model. J. Clim., 1, 841-866.

Mengel, J.G., D.A. Short, and G.R. North. 1988. Seasonal snowline instability in an energy balance model. Climate Dyn., 2, 127-131.

Morel, P. and E. Irving. 1978. Tentative paleocontinental maps for the early Phanerozoic and Proterozoic. J. Geol., $86,535-561$.

North, G.R. 1975. Theory of energy-balance climate models. J. Atmos. Sci., 32, 2033-2043.

North, G.R. 1984. The small ice cap instability in diffusive climate models. J. Atmos. Sci., 41, 3390-3395.

North, G.R. and J.A. Coakley. 1979. Differences between seasonal and mean annual energy balance model calculations of climate and climate sensitivity. J. Atmos. Sci., 36, 1189-1204.

North, G.R. and T.J. Crowley. 1985. Application of a seasonal climate model to Cenozoic glaciation. J. Geol. Soc., London, 142, 475-482.

North, G.R., R.F. Cahalan, and J.A. Coakley. 1981. Energy balance climate models. Rev. Geophys. Space Phys., 19, 91-121.

North, G.R., J.G. Mengel, and D.A. Short. 1983. Simple energy balance model resolving the seasons and the continents: application to the astronomical theory of the ice ages. J. Geophys. Res., 88(C11), 6576-6586.

Peterson, W.H. 1979. A steady thermohaline convection model. Coral Gables, FL, University of Miami. Rosenstiel School of Marine and Atmospheric Science. (Technical Report TR-79-4.)

Ruddiman, W.F., W.L. Prell, and M.E. Raymo. 1989. History of Late Cenozoic uplift in southeast Asia and the American southwest: rationale for general circulation modeling experiments. J. Geophys. Res., 94(D15), $18,379-18,391$.

Saltzman, B. and A. Sutera. 1984. A model of the internal feedback system involved in late Quaternary climatic variations. J. Atmos. Sci., 41, 736-745.

Suarez, M.J. and I.M. Held. 1979. The sensitivity of an energy balance climate model to variations in the orbital parameters. J. Geophys. Res., 84(C8), 4825-4836.

Watts, R.G. and M.E. Hayder. 1984. The effect of land-sea distribution on ice-sheet formation. (Abstract.) Ann. Glaciol., 5, 234-236. 